\title{
Repositioning of Immunomodulators: A Ray of Hope for Alzheimer's Disease?
}

\author{
Antonio Munafò ${ }^{11}$, Chiara Burgaletto ${ }^{1 t}$, Giulia Di Benedetto', Marco Di Mauro', \\ Rosaria Di Mauro ${ }^{1}$, Renato Bernardini ${ }^{1,2 *}$ and Giuseppina Cantarella ${ }^{1}$ \\ ${ }^{1}$ Department of Biomedical and Biotechnological Sciences, Section of Pharmacology, University of Catania, Catania, Italy, \\ ${ }^{2}$ Unit of Clinical Toxicology, University Hospital, University of Catania, Catania, Italy
}

OPEN ACCESS

Edited by: Anna R. Carta,

University of Cagliari, Italy

Reviewed by:

Dan Frenkel,

Tel Aviv University, Israel Anna Pannaccione,

University of Naples Federico II, Italy

*Correspondence:

Renato Bernardini bernardi@unict.it

${ }^{\dagger}$ These authors have contributed equally to this work

Specialty section: This article was submitted to

Neuropharmacology,

a section of the journal

Frontiers in Neuroscience

Received: 06 October 2020 Accepted: 12 November 2020 Published: 04 December 2020

Citation:

Munafò $A$, Burgaletto $C$ Di Benedetto G, Di Mauro M,

Di Mauro R, Bernardini R and

Cantarella G (2020) Repositioning of Immunomodulators: A Ray of Hope

for Alzheimer's Disease?

Front. Neurosci. 14:614643.

doi: 10.3389/fnins.2020.614643
Alzheimer's disease (AD) is the most common age-related neurodegenerative disorder characterized by cognitive decline and by the presence of amyloid $\beta$ plaques and neurofibrillary tangles in the brain. Despite recent advances in understanding its pathophysiological mechanisms, to date, there are no disease-modifying therapeutic options, to slow or halt the evolution of neurodegenerative processes in AD. Current pharmacological treatments only transiently mitigate the severity of symptoms, with modest or null overall improvement. Emerging evidence supports the concept that $A D$ is affected by the impaired ability of the immune system to restrain the brain's pathology. Deep understanding of the relationship between the nervous and the immune system may provide a novel arena to develop effective and safe drugs for AD treatment. Considering the crucial role of inflammatory/immune pathways in $A D$, here we discuss the current status of the immuno-oncological, immunomodulatory and anti-TNF- $\alpha$ drugs which are being used in preclinical studies or in ongoing clinical trials by means of the drug-repositioning approach.

Keywords: disease-modifying therapy, clinical trial, drug repurposing, immune response, neuroinflammation

\section{INTRODUCTION}

Alzheimer's disease (AD) is the most common cause of dementia worldwide, characterized by highest clinical unmet need and huge overall disease burden (Citron, 2010; Lo et al., 2014). AD manifests as a devastating neurodegenerative disorder that, inexorably upset memory, cognitive functions, and the ability to carry out common daily activities (Fischer et al., 2008). The presence in the brain of amyloid beta $(A \beta)$ plaques, composed of $A \beta$ protein and intracellular neurofibrillary tangles, constituted by hyperphosphorylated tau protein, are the two cardinal pathological hallmarks of AD (Querfurth and LaFerla, 2010; Edler et al., 2017; Bulk et al., 2018). Several other hypotheses have been suggested on the pathogenesis of $\mathrm{AD}$, such as neuronal loss, axonal injury, and dysfunction of cholinergic neurotransmission (Hardy and Selkoe, 2002; Haam and Yakel, 2017).

Abbreviations: AD, Alzheimer's disease; APCs, antigen presenting cells; $\mathrm{A} \beta$, amyloid beta; $\mathrm{BBB}$, blood brain barrier; CNS, central nervous system; CSF, cerebrospinal fluid; GA, glatiramer acetate; ICR, inhibitory immune checkpoint receptor; IFN$\gamma$, interferon gamma; IMiDs, immunomodulatory imide drugs; Mo, monocytes; MS, multiple sclerosis; mTOR, mechanistic target of rapamycin; $\mathrm{M} \Phi$, macrophages; NMDA, $N$-methyl-D-aspartate; PD-1, programmed cell death protein-1; PD-L1, programmed cell death ligand-1; Pom, Pomalidomide; sAPP, secreted amyloid precursor protein; TBI, traumatic brain injury; TRAIL, tumor necrosis factor-related apoptosis inducing ligand; Treg, regulatory $\mathrm{T}$ cells. 
Recent GWAS studies, demonstrating the role of specific genetic variance affecting APP and $\mathrm{A} \beta$ processing, showed, at the same time, a tight correlation between immune gene expression and the progression of $\mathrm{AD}$, confirming the crucial role of neuroimmune interactions (Kunkle et al., 2019).

Chronic neuroinflammation is one of the main leitmotiv driving current hypotheses in support of the pathogenesis of AD (Scuderi et al., 2020). Such phenomenon largely derives from aberrant activation of microglia, the brain resident mononuclear phagocytes physiologically involved in central immune surveillance and clearance of pathogens (Burgaletto et al., 2020; Ní Chasaide and Lynch, 2020).

Neuroinflammatory foci in $\mathrm{AD}$ localize in close vicinity of $A \beta$ plaques and it is associated with glia activation (Bronzuoli et al., 2016) and the consequent release of inflammatory/immune mediators (Chakraborty et al., 2010), including pro-inflammatory cytokines (Griffin, 2013; Cantarella et al., 2015). In AD, neuroinflammation, instead of being a mere bystander activated by emerging senile plaques and neurofibrillary tangles, substantially contributes to the pathogenesis, synergistically to either $A \beta$ plaques or neurofibrillary tangles (Zhang et al., 2013).

There is also a great deal of evidence suggesting a role of relevance for systemic inflammation in the pathogenesis of $\mathrm{AD}$ (Heneka et al., 2015; Ardura-Fabregat et al., 2017; Paouri and Georgopoulos, 2019). Systemic inflammation in AD is associated with an exacerbation of sickness behavior symptoms due to the increased central release of pro-inflammatory cytokines but, importantly, it also acts to accelerate disease progression due to the augmented production of reactive oxygen species and prominent neuronal death (Perry et al., 2010).

In addition to the central nervous system (CNS) resident immune cells, emerging evidence has supported the hypothesis of a relevant role to the peripheral immune system in maintenance of brain homeostasis (Kipnis et al., 2004; Ziv et al., 2006; Filiano et al., 2016) and in disease pathogenesis (Raposo et al., 2014; Baruch et al., 2015; Zenaro et al., 2015; Di Benedetto et al., 2019).

Immune checkpoints are crucial factors in regulating systemic immune homeostasis and tolerance. Selective blockade of some immune checkpoints, such as the Programmed cell death protein-1 (PD-1)/programmed cell death ligand-1 (PD-L1) pathway, enhances anti-tumor immunity by resetting into motion the immune response (Lesokhin et al., 2015). Notwithstanding poor evidence is currently available about the influence of peripheral immune response upon $\mathrm{AD}$ brain pathology and related clinical outcomes (Trapnell et al., 2009; Heinz et al., 2010), more recent data suggest that, not only peripheral immunocytes can enter the brain, but also their modulation impacts on its progression (Schwartz and Baruch, 2014; Di Benedetto et al., 2019). Immune modulation in animal models of $\mathrm{AD}$ and dementia achieved through treatment with anti-PD-1 or anti-PD-L1 antibodies approaches, resulted in disease modification, manifested by milder pathology paralleled by cognitive improvement (Baruch et al., 2016; Rosenzweig et al., 2019; Castellani and Schwartz, 2020).

Despite the wide number of clinical trials (Cummings et al., 2020), there are currently only four approved pharmacotherapies for AD. Three acetylcholinesterase inhibitors (donepezil, rivastigmine, and galantamine) are recommended as options in the treatment of patients with mild to moderate $\mathrm{AD}$; and memantine, an $N$-methyl-D-aspartate (NMDA) receptor antagonist, is licensed for the management of patients with moderate to severe $\mathrm{AD}$. These agents represent symptomatic treatments, and they do not act as disease modifying drugs, as they only temporarily ameliorate cognitive dysfunction, with relatively modest clinical impact (Cummings et al., 2016).

Drug repositioning represents a valid approach for drug discovery, consisting of finding new indications for currently available drugs used in different clinical settings whose safety and tolerability have already been confirmed (Pillaiyar et al., 2020). For all the above-mentioned reasons, drug repurposing represents a useful tool in searching new treatments for $\mathrm{AD}$ (Ihara and Saito, 2020).

Keeping in mind the central role of neuroinflammation, various anti-inflammatory compounds have been re-proposed in $\mathrm{AD}$ treatment.

In the wake of several preclinical studies, clinical trials carried out to verify the efficacy of non-steroidal anti-inflammatory drugs (NSAIDs) as curative drugs for $\mathrm{AD}$ have failed to show promising results (Ali et al., 2019).

In addition, several drugs indicated for multiple myeloma or leukemia, including daratumumab (anti-CD38 antibody) (Blacher et al., 2015), dasatinib (tyrosine kinase inhibitor) (Zhang et al., 2019), lenalidomide (thalidomide analog; TNFalpha inhibitor) (He et al., 2013), and sargramostim (granulocyte macrophage colony stimulator) (Kiyota et al., 2018), have been explored for efficacy in $\mathrm{AD}$, based on their immunomodulatory properties assessed in cellular or animal models of $\mathrm{AD}$ (Ihara and Saito, 2020).

Considering the key role of the immune/inflammatory response in the development of $\mathrm{AD}$, in the present review we summarize information available concerning the most promising immunomodulatory agents already used in other disease settings for repurposing in $\mathrm{AD}$. In the following sections we will discuss the preclinical evidences underlying possible positioning of each drug in the $\mathrm{AD}$ frame. In another section, we will reason about some of the agents which are being studied in ongoing clinical trials.

\section{PRECLINICAL EVIDENCE}

\section{Immuno-Oncologic Drugs: A Therapeutic Breakthrough in Cancer With a Regard to Neurodegeneration?}

Growing body of evidence from multiple studies focus on an inverse epidemiological relationship between $\mathrm{AD}$ and cancer. In fact, patients with previous history of cancer have a lower risk of developing $\mathrm{AD}$, otherwise patients suffering from $\mathrm{AD}$ show less risk of developing cancer (Rogers et al., 2020).

Research also proved that chemotherapy-treated breast cancer survivors have shown a lower risk of $\mathrm{AD}$ compared to healthy control (Monacelli et al., 2017). 
Common biological and genetic mechanisms deregulated in opposite directions could explain the phenomenon of mutual protection between $\mathrm{AD}$ and cancer (Houck et al., 2018; Okereke and Meadows, 2019). Chronic neuroinflammation related to $\mathrm{AD}$ could protects against cancer, otherwise cancer development induces a persistent state of immune tolerance that protects against AD (Rogers et al., 2020). Deep understanding of these mechanisms could represent a trail to follow for designing disease-modifying therapeutic interventions and many anti-cancer agents are the path of repurposing for the treatment of $\mathrm{AD}$. Immunotherapy, helping the immune system to ward off disease, has revolutionized the landscape of cancer treatment and may offer new hope for $\mathrm{AD}$ (Figure 1).

\section{Immune Checkpoints Inhibitors: PD1 and PD-L1}

Programmed cell death protein-1, an inhibitory immune checkpoint receptor (ICR) expressed by immune cells such as T cells, and its broadly expressed ligand PD-L1, have emerged as critical inhibitory signaling pathway that assumes a critical role in maintaining immune homeostasis and self-tolerance preventing autoimmune reaction (Riella et al., 2012; Zhao and Ji, 2019).

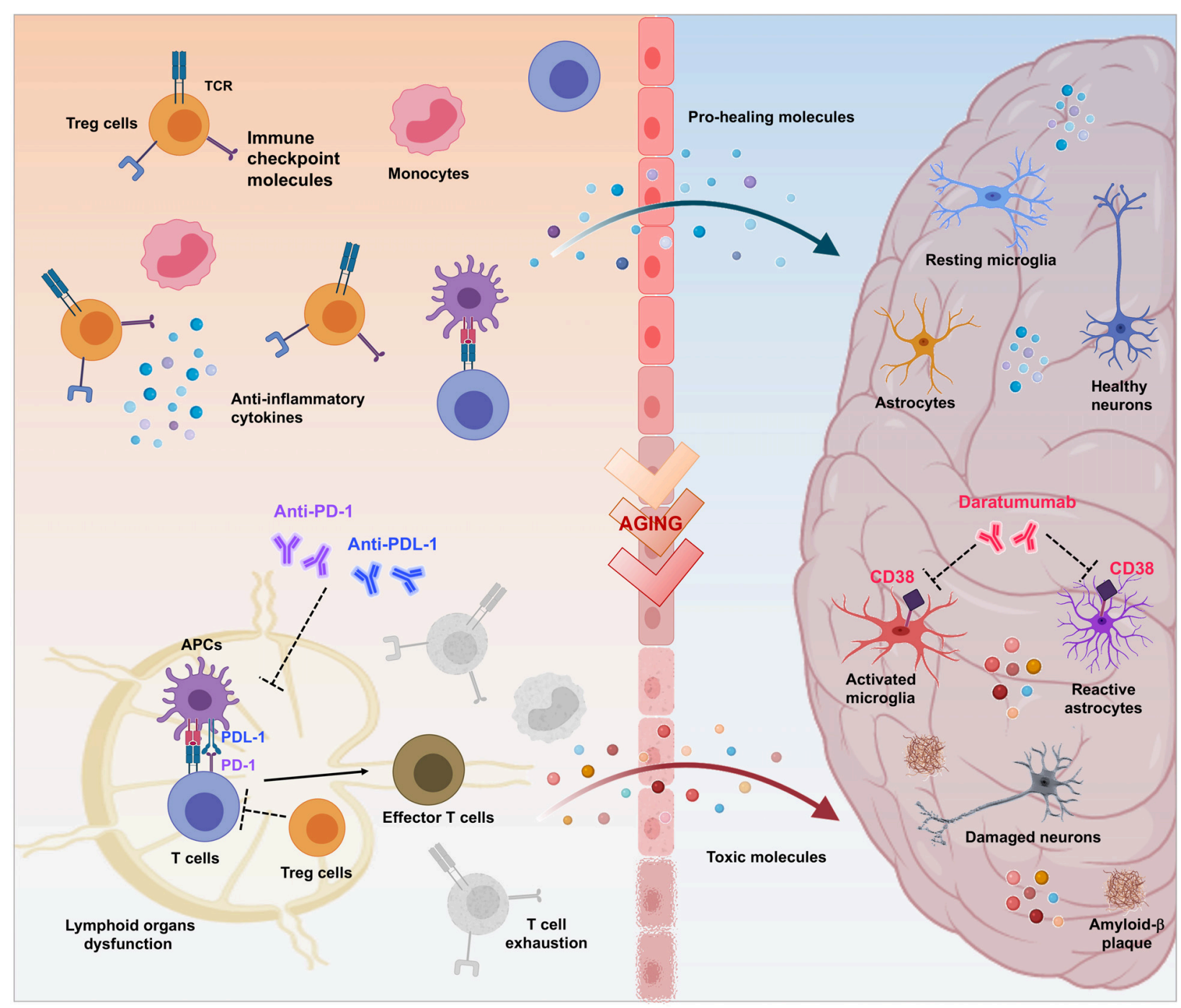

FIGURE 1 | Therapeutic potential of immuno-oncologicals in Alzheimer's Disease. Immuno-oncological drugs could mark the beginning of a new era for treatment of AD-related neurodegeneration aimed to revitalize the body's immune-mediated repair mechanisms by addressing multiple pathophysiological factors. As in cancer scenario, controlled trafficking of healing immunocytes to the injured brain could be considered as a mean to overcome immune escape mechanisms and to modify AD progression. Breaking regulatory T cell (Treg)-mediated systemic immune suppression and blocking inhibitory immune checkpoints, such as PD-1/PD-L1 with specific antibodies represents a crucial approach to enhance recruitment of pro-healing immunocytes to the brain parenchyma, culminating in attenuation of the disease-associated pathological features (e.g., dysfunction of lymphoid organs, increase of exhausted T cells, neuroinflammation, production of toxic proteins, neuronal damage and death). Moreover, release of proinflammatory factors that occurs in the brain during aging and AD, results in augmented expression of CD38 in glial cells, amplifying the neurodegenerative cycle. In turn, targeting CD38 with Daratumumab may represent a novel therapeutic approach for modulation of both $A D$-related neuroinflammation and $A \beta$ production. 
In pathological conditions, such as cancer and viral infection, persistent antigen stimulation and inflammation increase the expression level of these ICRs at the $\mathrm{T}$ cell surface and its interaction with its ligand on antigen presenting cells (APCs) limit $\mathrm{T}$ cell activation, by inducing a hypofunctional state called "exhaustion" (Chamoto et al., 2017; Curdy et al., 2019). This mechanism has emerged as a conceivable therapeutic target for either enhancing or dampening the immune response. Immunosuppressive regulatory $\mathrm{T}$ cells (Treg), recruited by abnormal cancer cell chemotactic activity, would have a pivotal role in this process (Baruch et al., 2015).

The development of monoclonal antibodies that target immune checkpoints represents a revolutionary milestone in the field of immuno-oncology (Darvin et al., 2018; Havel et al., 2019) for their ability to modulate the immune response against cancer (Saibil and Ohashi, 2020).

Anti-PD-1/PD-L1 based immunotherapy used as an effective treatment strategy for a wide variety of cancers, including those traditionally considered non-immunogenic (Santarpia et al., 2015), has been recently considered also in animal model of $\mathrm{AD}$ as it boosts immune response against the harmful proteins that cause neurodegeneration (Schwartz et al., 2019). Consistently, Cantarella et al. (2003, 2015) have shown that immunoneutralization of Tumor necrosis factor-related apoptosis inducing ligand (TRAIL), a pleiotropic proinflammatory cytokine which also modulates Treg cell functions, results in an improvement of neuroinflammation in a mouse model of AD (Di Benedetto et al., 2019).

Breaking immune tolerance by PD-1 immune checkpoint blockade elicited a stronger interferon (IFN)- $\gamma$-dependent systemic immune response, which is followed by the recruitment of monocyte-derived macrophages $(M \Phi)$ to the brain, leading to clearance of cerebral $A \beta$ plaques and improved cognition in mice with advanced amyloid pathology (Baruch et al., 2016; Rogers et al., 2020). More recently, it was demonstrated that PDL1 blockade have efficacy comparable to that of PD-1 blocking in disease modification in $\mathrm{AD}$ animal models. In particular, modification of the immunological milieu of the brain mediated by blockade of the PD-1/PD-L1 axis in a mouse model of tau pathology culminates in mitigation of cognitive deficits and cerebral pathology (Rosenzweig et al., 2019).

Consistently with these results, it has been demonstrated that functional PD-1 is expressed in hippocampal neurons and that anti-PD-1 treatment acts also as a neurotherapy potentiating learning and memory by rescue of synaptic transmission and plasticity (Zhao and Ji, 2019).

Conversely, several pharmaceutical companies, that were developing PD-1 antibody inhibitors for other pathologies, pursued this strategy with their own compounds in several $A \beta$ plaque transgenic models. As expected, PD-1 immunotherapy boosted activation of the peripheral immune system but failed to affect monocyte-derived macrophage infiltration and progression of brain $A \beta$ pathology in three different models of AD (Latta-Mahieu et al., 2018; Obst et al., 2018).

In addition, another research group reports only a modest improvement of locomotor activity without any effect on cognition or tau pathology in a transgenic AD model ( $\mathrm{Li}$ et al.,
2020) by using the same PD-1 checkpoint blockade approach (Baruch et al., 2016; Rosenzweig et al., 2019).

Although the immune checkpoint blockade based-therapy represents a promising therapeutic strategy for $\mathrm{AD}$ and agerelated dementia, further research is needed before PD-1/PD-L1 based clinical trials are conceived for these disorders.

\section{Daratumumab (CD38)}

Daratumumab is a first-in-class humanized monoclonal antibody that targets the CD38 epitope approved for multiple myeloma patients who are refractory to conventional therapy (van de Donk, 2018).

Given its role in regulation of neuroinflammatory and brain repair processes, the effect of depletion of CD38, a NAD glycohydrolase expressed by neurons, astrocytes and microglial cells, by daratumumab has been evaluated in the $\mathrm{AD}$ context (Guerreiro et al., 2020).

Deletion of CD38 results, in turn, in a significant reduction of $A \beta$ plaque load and soluble $A \beta$ levels and this correlated with improved spatial learning (Blacher et al., 2015).

While direct evidence implicating CD38 in neurodegenerative disorders is still lacking, targeting CD38 may provide a novel therapeutic approach for modulation of both neuroinflammation and $\mathrm{A} \beta$ production related to $\mathrm{AD}$.

\section{Immunomodulating Agents}

Immunomodulatory drugs have revolutionized the treatment protocols of various immune-related diseases. These compounds act through modification of the immune response, for example by increasing (immunostimulators) or decreasing (immunosuppressives) the production of serum antibodies (Bascones-Martinez et al., 2014).

Given that the multifactorial pathophysiological mechanism of $\mathrm{AD}$ is not restricted to the neuronal compartment, as relevant role has been attributed to the tight interactions of immunological mechanisms within the brain, the repositioning of immunomodulatory drugs could represent an attractive therapeutic strategy in the fight against AD (Figure 2).

\section{Glatiramer Acetate (Copaxone)}

Glatiramer acetate (GA) (Copaxone) is the first diseasemodifying and worldwide-approved drug for the treatment of relapsing-remitting multiple sclerosis (MS), an autoimmune disorder of the CNS (Arnon and Aharoni, 2019). GA is a synthetic analog of myelin basic protein (Scott, 2013), one of the autoantigens implicated in the pathogenesis of MS, which can be used to safely boost T-cell responses without the risk of autoimmune disease, as it weakly cross-reacts with myelinderived autoantigens (Chen et al., 2015). While the mechanism of action of GA remains a matter of ongoing debate, several evidences suggest that it stimulates Th2 response possibly by suppressing the inflammatory Th1 response (Vieira et al., 2003), increases frequency and function of Treg cells, modulates CD8+ $\mathrm{T}$ cells and exerts an immunomodulatory effect on B cells (Lalive et al., 2011).

Immunization of APPSWE/PS1dE9 double-transgenic mice with GA enhances cerebral recruitment of pro-healing, highly 


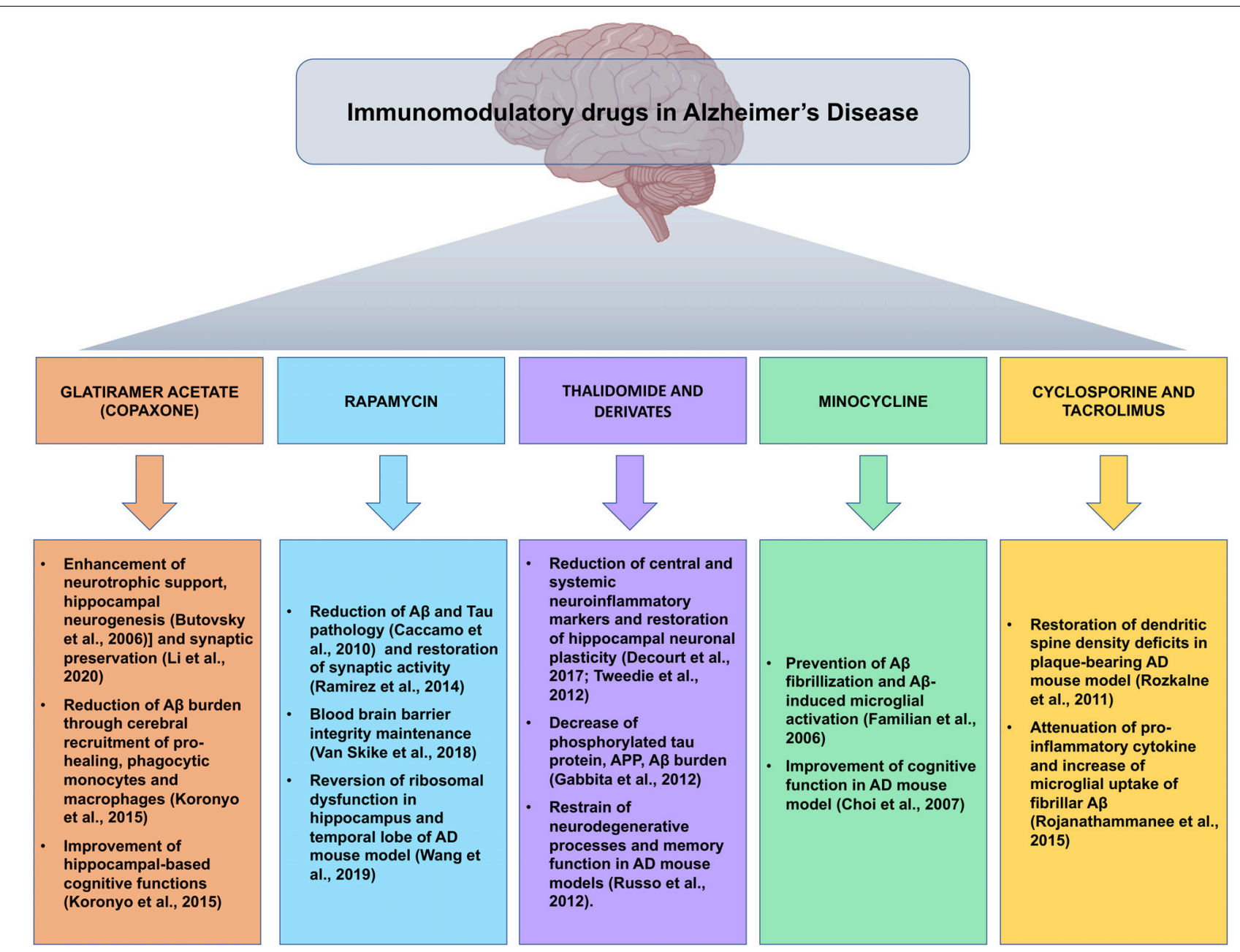

FIGURE 2 | Snapshot of the main preclinical evidences for the implications of immunomodulatory drugs repositioned for Alzheimer's disease. Summary of the most compelling preclinical evidences of the beneficial effects of immunomodulatory agents in the pathophysiological processes of Alzheimer's disease, in view of possible future clinical development of immunomodulatory drug-based therapeutic strategies.

phagocytic monocytes (Mo) and $M \Phi$, deeply alleviating cerebral $\mathrm{A} \beta$ burden, reducing microgliosis and astrocytosis, finally leading to improved hippocampal-based cognitive functions (Koronyo et al., 2015). Moreover, T cell-based vaccination with GA in the same animal model of $\mathrm{AD}$ leads to enhanced neurotrophic support and hippocampal neurogenesis (Butovsky et al., 2006).

Moreover, nasal vaccination with a proteosome-based adjuvant plus GA leads to activation of pro-healing microglia, strongly correlated with a decrease in A $\beta$ fibrils in APP-Tg mice (Frenkel et al., 2005).

Recently, it has been demonstrated both in in vivo and in vitro studies that GA-stimulated $M \Phi$ protect neurons from $A \beta$ mediated synaptotoxicity through enhanced ability to eliminate $\mathrm{A} \beta 42$ oligomers and induce synaptic preservation ( $\mathrm{Li}$ et al., 2020). Moreover, GA immunomodulation enhanced cerebral recruitment of Mo-derived $\mathrm{M} \Phi$ and reversed loss of cortical and hippocampal excitatory synapses in mouse models of $\mathrm{AD}$.

Consistently, it has been demonstrated that GA immunization significantly increases expression of hippocampal early growth response protein 1 (Egr1), protein required for synaptic plasticity and memory formation, which was negatively correlated with hippocampal A $\beta$ plaque burden (Bakalash et al., 2011).

GA-based vaccination could provide a new avenue for immune therapy that might prove efficacious in the treatment of $\mathrm{AD}$.

\section{Rapamycin}

Rapamycin is a macrolide antibiotic and inhibitor of the mechanistic target of rapamycin (mTOR) that exhibits potent anti-cancer and immunosuppressive activity (Law, 2005) originally used to prevent organ transplant rejection (Richardson et al., 2015).

Currently, this drug represents the most effective pharmacological approach for directly targeting hallmarks of the aging process in order to increase lifespan in several animal models.

In addition to its efficacy at mitigating physiological aging, this drug has been shown to have a beneficial effect in models 
of neurodegeneration and aging, including mouse models of $\mathrm{AD}$ (Kaeberlein and Galvan, 2019).

The positive outcomes of rapamycin treatment probably stand up on its ability to rescue molecular pathways associated with aberrant mTOR phosphorylation, responsible to speed up the age-related neurodegenerative process and increase the risk of developing AD (Caccamo et al., 2010).

In fact, it has been demonstrated that restoring mTOR signaling with rapamycin ameliorates $A \beta$ and tau pathology in several mouse models, preserves blood brain barrier (BBB) integrity, restores cerebral blood flow and brain vascular density and rescues cognitive deficits (Lin et al., 2013; Van Skike et al., 2018; Gureev et al., 2020).

Rapamycin is also able to regulate cholesterol biosynthesis, essential for synaptic formation and to reverse ribosomal dysfunction in hippocampus and temporal lobe of APP/PS1 mouse (Wang et al., 2019). In addition, rapamycin protects hippocampal neurons from synaptotoxicity induced by $A \beta$ oligomers by increasing presynaptic activity (Ramírez et al., 2014).

Similarly, chronic treatment with the rapamycin derivative temsirolimus, a recently developed compound used for renal cell carcinoma treatment, promotes autophagic $\mathrm{A} \beta$ clearance, reduces neurofibrillary tangle density and attenuates apoptosis in hippocampus, leading to a substantial improvement in spatial learning and memory abilities (Jiang et al., 2014).

Conversely, one study revealed that rapamycin can only prevent, but not rescue, the accumulation of amyloid plaques and tangles, as well as cognitive deficits (Majumder et al., 2011).

Current preclinical data reveals that rapamycin may be valuable for preventing the onset or early $\mathrm{AD}$ neuropathology, and, however, cannot represents a treatment option in people with overt clinical signs of dementia. Altogether, it is plausible to propose rapamycin as an agent that, if used in the prodromic stages of $\mathrm{AD}$, would probably demonstrate effectiveness in delaying progression of dementia.

\section{Thalidomide and Its Derivatives}

Thalidomide and its derivatives, referred to as immunomodulatory imide drugs (IMiDs), are a class of drugs that target the $3^{\prime}$-untranslated region (3'-UTR) of Tumor necrosis factor alpha (TNF- $\alpha$ ) mRNA, inhibiting TNF- $\alpha$ cytokine production. Preclinical studies on currently marketed IMiDs, indicate improved BBB permeability and bioavailability when compared to similar anti-inflammatory agents, supporting the concept of their development as drugs for neurological disorders (Jung et al., 2019).

Thalidomide is a potent immunomodulator and a TNF- $\alpha$ inhibitor, originally used for treatment of multiple myeloma and erythema nodosum leprosum (Jung et al., 2019) and evaluated for repurposing across numerous neurological disorders due to its multipotent pleiotropic characteristics.

Chronic thalidomide administration significantly blunts both astrocytes and microglia activation, and $A \beta$ generation in brains of APP23 transgenic mice through inhibition of beta-secretase (BACE1) (He et al., 2013; Decourt et al., 2017).
Moreover, 3,6'-dithiothalidomide (3,6'-DT) effectively lowers TNF- $\alpha$, nitrite and secreted amyloid precursor protein (sAPP) levels in vitro in LPS-activated macrophage-like cells, while it significantly reduces central and systemic TNF- $\alpha$ production, neuroinflammatory markers and restores hippocampal neuronal plasticity in LPS-challenged rats (Tweedie et al., 2012). Chronic 3,6'-DT administration reduces multiple hallmark features of $\mathrm{AD}$, including glia activation, phosphorylated tau protein, APP, $A \beta$ peptide and $A \beta$-plaque number along cognitive dysfunction in $3 \times \mathrm{Tg}-\mathrm{AD}$ mice, and leads to synaptic preservation (Gabbita et al., 2012; Tweedie et al., 2012). As a matter of fact, 3,6'-DT ameliorates $\mathrm{A} \beta$-induced neuroinflammation and microglial activation, preventing neurodegeneration and improving memory in $\mathrm{AD}$ mouse model of stereotaxic intracerebroventricular $A \beta 1-42$ (Russo et al., 2012).

Recently, it has been demonstrated that also Pomalidomide (Pom), an immunomodulatory amino-thalidomide analog, and Pom analog 3,6'-dithioPom (DP), significantly mitigate Traumatic brain injury (TBI)-induced cell death, neurodegeneration, astrogliosis, microglial activation, neuroinflammation and behavioral impairments in TBI which represents a process tightly associated with the later development of dementia (Lin et al., 2020).

Taken together, these preclinical studies using IMiDs have shown promising profiles, indicating a potential for the promotion of this therapeutic class from the bench to clinical trials and eventually, to the bedside of $\mathrm{AD}$ patients.

\section{Minocycline}

Minocycline is a member of tetracycline family antibiotic with anti-inflammatory and immunomodulatory properties, largely used in the treatment of acne vulgaris and various sexually transmitted diseases (Garrido-Mesa et al., 2013). Based upon its ability to cross the BBB and to inhibit microglial cells, minocycline has been regarded as a repurposing candidate for evaluation in $\mathrm{AD}$ (Shamim and Laskowski, 2017).

Minocycline prevents $A \beta$ fibrillization and $A \beta$-induced microglial activation in vitro (Familian et al., 2006) leading to attenuation of inflammatory response and microgliosis, as well as to a significant improvement of cognitive deficit (Fan et al., 2007). Similar beneficial effects on cognitive functions were obtained in a A $\beta 1$-42-infused rat model and $\operatorname{Tg} 2576$ mice treated intraperitoneally with minocycline (Choi et al., 2007).

Moreover, it has been reported that minocycline has different effects on $A \beta$ plaque deposition depending upon the age of administration, due to its action on microglial function (Fu et al., 2019). In addition, minocycline is able to significantly restrain the early, pre-plaque neuroinflammatory response, and also to reduce APP expression; moreover, it inhibits BACE1 activity in McGill-Thy1-APP mice (Ferretti et al., 2012).

Minocycline is able to reduce microglia reactivity in the dentate gyrus, as well as inducible nitric oxide synthase protein levels and reactivity of $A \beta$ plaque-associated $C D 11 b+$ microglia in the hippocampus of APP/PS1 mice (Biscaro et al., 2012). 


\section{Cyclosporine and Tacrolimus}

Inhibitors of calcineurin such as Cyclosporine and Tacrolimus, are immunosuppressive agents used for the prophylaxis of post-transplant organ rejection and to treat autoimmune diseases (Khanna, 2000).

In the $\mathrm{AD}$ scenario, these agents downregulate the expression of APP mRNA and protein in primary cultures of neonatal rat astrocytes (Lee et al., 1999).

Furthermore, short-term treatment with tacrolimus ameliorates dendritic spine density deficits in plaque-bearing AD model mice (Rozkalne et al., 2011).

More recently, it has been demonstrated that Tacrolimus significantly attenuated both $\mathrm{A} \beta$ - and LPS-stimulated secretion of pro-inflammatory cytokines and increased microglial uptake of fibrillar $\mathrm{A} \beta$ in vitro, while it led to decreased spleen cytokine levels, microgliosis and A $\beta$ plaque burden in APP/PS1 mice (Rojanathammanee et al., 2015). Cyclosporine and Tacrolimus treatment significantly attenuates Streptozocininduced biochemical and histopathological alterations and age-related memory deficits. This evidence demonstrates the potential of these agents in cognitive dysfunctions, probably related to their anti-amyloid, anti-oxidative and anti-inflammatory properties (Kumar and Singh, 2017).

\section{TNF- $\alpha$ Blocking Agents}

TNF- $\alpha$ is a potent proinflammatory cytokine that plays a central role in setting into motion and sustaining the inflammatory response.

TNF- $\alpha$ signaling exerts both homeostatic and pathophysiological roles in the CNS.

In the healthy CNS, TNF- $\alpha$ has regulatory functions on synaptic plasticity, control of microglial activation and astrocyteinduced synaptic strengthening, and regulation of glutamatergic transmission (Belarbi et al., 2012; Olmos and Lladó, 2014).

In pathological conditions, microglia release large amounts of TNF- $\alpha$ that represents a critical mediator of neuronal dysfunction and cognitive impairment consequent to chronic neuroinflammation (Olmos and Lladó, 2014).

TNF- $\alpha$ contributes to disease onset and progression in transgenic mouse models of AD (Chang et al., 2017).

Clinical involvement of TNF- $\alpha$ in $\mathrm{AD}$ has been evidenced by the observation of elevated TNF- $\alpha$ levels in the plasma and in the cerebrospinal fluid (CSF) of AD patients and by the co-localization of TNF- $\alpha$ with $A \beta$ plaques in the brain, both correlated with disease severity (Steeland et al., 2018).

Several TNF- $\alpha$-specific monoclonal antibodies (e.g., infliximab, adalimumab) and recombinant fusion proteins (etanercept), often developed for peripheral inflammatory conditions including Crohn's disease and rheumatoid arthritis, have been tested on AD rodent models using both central and peripheral routes of administration (Chang et al., 2017; Decourt et al., 2017). Treatment with TNF-blocking agents in patients with rheumatic disorders is associated with lower risk for $\mathrm{AD}$ development (Zhou et al., 2020).

Nevertheless, limited BBB penetration of these agents is the main drawback for their development (Chang et al., 2017). Thus, peripheral targeting of TNF- $\alpha$ activity and reengineering of the TNF- $\alpha$ inhibitors able to cross BBB represent two methods to reasonably overcome such limitations (Yiannopoulou and Papageorgiou, 2020).

However, targeting TNF- $\alpha$ synthesis with inhibitors (Figure 3) has also been proposed to have a great potential for the long-term prevention and treatment of AD (Belarbi et al., 2012).

\section{Etanercept}

Etanercept, a bio-engineered, anti-rheumatoid, anti-TNF- $\alpha$ fusion protein that binds both soluble and membrane-bound forms of TNF- $\alpha$, has been re-evaluated also as a treatment to hold off central and peripheral immune/inflammatory response in $\mathrm{AD}$ (Butchart et al., 2015).

Peripheral administration of etanercept counteracts $\mathrm{A} \beta$-induced memory impairment and attenuates hippocampal levels of TNF in a non-transgenic mouse model of amyloid induced cognitive deficits (Detrait et al., 2014; Chang et al., 2017).

Recent evidence reports that etanercept leads to a decrease of plaques burden and neurofibrillary tangles and improves cognitive outcomes in streptozocin-treated rats, widely used to mimic an AD-like condition in animal models (Kübra Elçioğlu et al., 2015).

Although there are many evidences for the beneficial effect of etanercept, it still remains to be explored whether this drug is able to alter $\mathrm{AD}$-like neuropathology in $\mathrm{AD}$ chronic models.

\section{Infliximab}

Infliximab is a monoclonal antibody against TNF- $\alpha$ approved for treatment of rheumatoid arthritis, Crohn's disease and other immune-mediated inflammatory disorders (Melsheimer et al., 2019).

Intracerebroventricular injection of Infliximab, beside reducing levels of $\mathrm{TNF}-\alpha$, induced rapid and transient decline in $\mathrm{A} \beta$ loads and tau phosphorylation in the APP/PS1 double transgenic mice (Shi et al., 2011).

Recently, it has been also demonstrated that infliximab dramatically improves visual recognition memory impaired by $\mathrm{A} \beta$ oligomers and reverses the noxious effect of $\mathrm{A} \beta$ on muscarinic acetylcholine receptor-dependent long-term depression of synaptic transmission in Tg2576 mice (Kim et al., 2016; Chang et al., 2017). Kübra Elçioğlu et al. (2015) reported also that infliximab, as demonstrated for etanercept, led to a significant improvement of cognitive functions in rat models of dementia.

Peripheral inhibition of TNF- $\alpha$ with infliximab in the context of arthritis, modulates the amyloid pathology by regulating blood-derived and local brain inflammatory cell populations involved in $\beta$-amyloid clearance in the brain of double-transgenic 5XFAD/Tg197 AD/TNF mice that develop amyloid deposits and inflammatory arthritis induced by human TNF- $\alpha$ expression (Paouri et al., 2017).

Despite these favorable evidences, other preclinical studies in mouse AD models with TNF- $\alpha$ inhibitors failed to reproduce such beneficial effects (Giuliani et al., 2009; Chang et al., 2017).

\section{Adalimumab}

Adalimumab, another anti-TNF- $\alpha$ monoclonal antibody, binds directly to TNF- $\alpha$ or to soluble and membrane-TNF- $\alpha$ receptors blocking ligand-receptor interactions (Scheinfeld, 


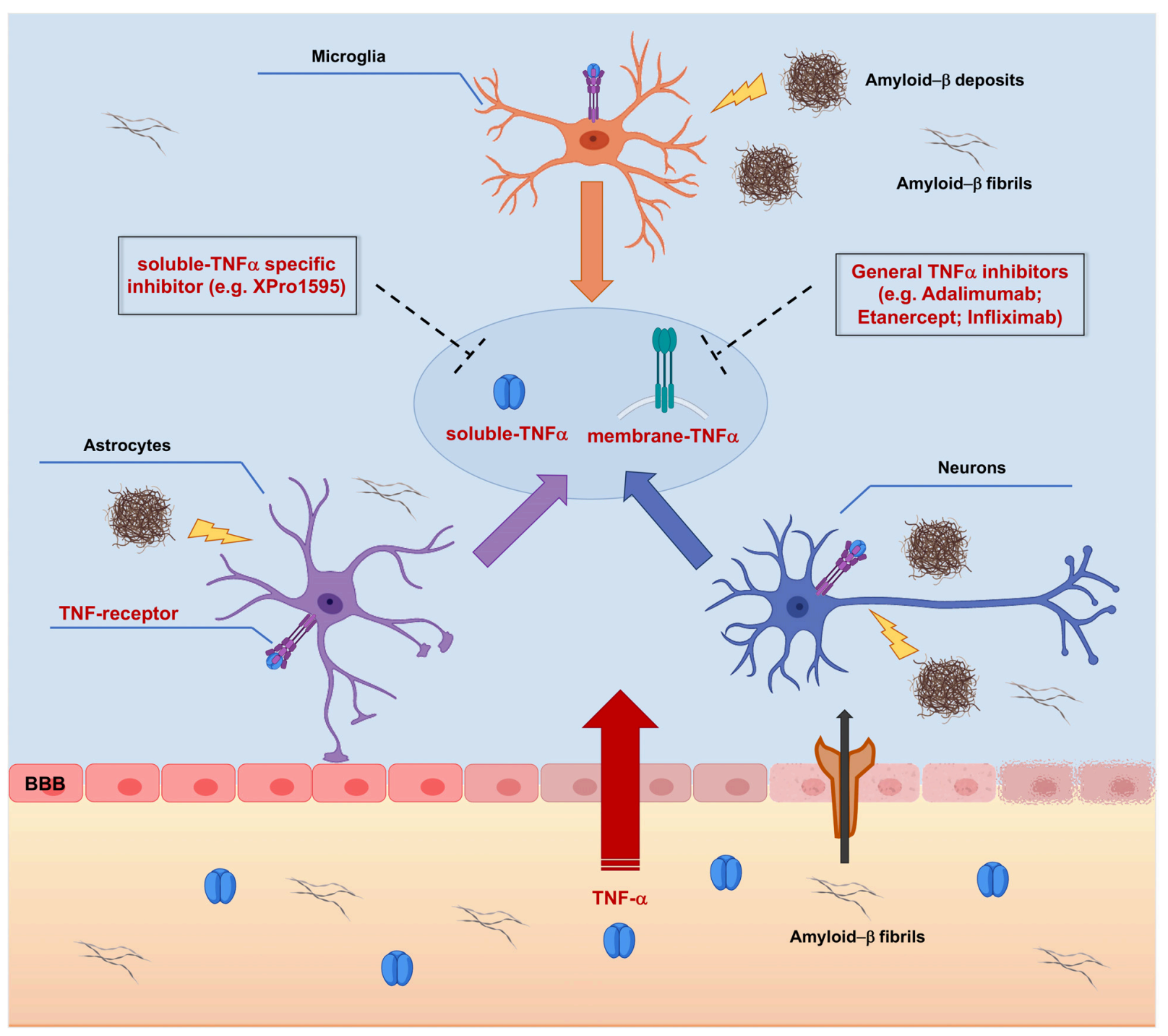

FIGURE 3 | Targeting TNF- $\alpha$ signaling with TNF- $\alpha$ inhibitors in Alzheimer's Disease pathology. Peripheral Tumor Necrosis Factor- $\alpha$ (TNF- $\alpha$ ) enters the brain through the Blood-Brain Barrier (BBB) via transcytosis, upsetting its structural integrity and the permeability. TNF- $\alpha$ affects brain resident cells by binding Tumor Necrosis Factor Receptors (TNFRs), thus triggering activation of different intracellular cascades which redundantly lead to increased release of TNF- $\alpha$. In addition, TNF- $\alpha$ leads to increased peripheral amyloid- $\beta(A \beta)$ influx and generation of amyloid deposits into the brain parenchyma, which supplement the local amyloid burden, causing further production of TNF- $\alpha$. Targeting membrane bound and/or soluble TNF $\alpha$ with small molecule inhibitors could represent a potential effective therapeutic approach acting at earliest steps of the AD-related neuroinflammatory vicious cycle, resulting in neuroprotection.

2005). Adalimumab has demonstrated efficacy and tolerability in patients with a wide range of inflammatory conditions (Lapadula et al., 2014).

Adalimumab treatment leads to significantly attenuated neuronal damage and neuroinflammation, decreased beta secretase-1 protein expression and $A \beta 1-40$ plaques, and to improvement of cognitive functions in $A \beta 1-40$-injected mice (Park et al., 2019; Anwar and Rivest, 2020), supplying a rationale for a hypothesis of clinically meaningful outcomes in patients with $\mathrm{AD}$.

\section{XPro1595}

XPro1595 is a second-generation TNF- $\alpha$ inhibitor, which, unlike etanercept and other non-selective TNF- $\alpha$ inhibitors, solely targets the soluble form of TNF- $\alpha$, preserving the neuroprotective transmembrane TNF- $\alpha$ signaling pathways (Steed et al., 2003).

Preclinical XPro1595 evaluation has been reported in three different mouse models of AD. Peripheral administration of the soluble TNF- $\alpha$ inhibitor XPro1595 is able to reduce brain amyloid deposition, age-dependent increase in activated immune cells and to improve synaptic function (Cavanagh et al., 2016; MacPherson et al., 2017). Local administration of XPro1595 leads to reduced pre-plaque $\mathrm{A} \beta$ pathology in $3 \times \mathrm{TgAD}$ mice (McAlpine et al., 2009), and, consistently, it reduces microglia activation and improves synaptic and cognitive functions in aging rats (Sama et al., 2012). 


\section{CLINICAL EVIDENCES}

Based on preclinical data, in recent years, numerous clinical trials have been conducted aimed to deepen the therapeutic potential of the above-mentioned drug classes for AD. However, most have failed to demonstrate promising results, probably because of the still incomplete understanding of the role of neuroinflammation in the development of $\mathrm{AD}$ combined to the lack of apposite diagnostic tools to determine stages of the disease (Cummings et al., 2020).

In this section, we report ongoing clinical trials that employ the drug-repositioning method for drug discovery of $\mathrm{AD}$ (Table 1).

\section{Daratumumab (NCT04070378)}

Currently Daratumumab is the only monoclonal antibody in study for drug repositioning in $\mathrm{AD}$. The rationale behind the use of this drug lies in its immunomodulatory action against CD38+ cells.

As mentioned above, CD38 is a multifunctional protein with both a receptor and an enzyme-mediated function involved in several important reactions for the physiological neuronal development (Guerreiro et al., 2020).

CD38 expression increases during neuroinflammation and neurodegeneration, suggesting its potential modulating role in brain cells regulation. Experiments on CD38 knockout mice (Roboon et al., 2019), demonstrated a decreased release of pro-inflammatory cytokines and chemokines (Kou et al., 2009), while its overexpression was found after treatment with drugs-induced neuroinflammation (Guerreiro et al., 2020).

Interestingly, CD38 expression on CD8+ T-cells is significantly increased in $\mathrm{AD}$ patients as compared with age-matched controls (Gate et al., 2020) and these activated T-cells are able to infiltrate into the CNS exerting toxic effects.

The objective of the clinical trial has been to explore whether treatment with Daratumumab, an agent able to cross the $\mathrm{BBB}$, may have a clinically meaningful effect on patients with mild to moderate AD.

The study includes patients with diagnosis of $\mathrm{AD}$, without a clinical history of other neurological or psychiatric disorders, according to NIA-AA criteria, a MMSE score between 15 and 26 and positive instrumental with MRI and amyloid PET scan, on a stable dose of cholinesterase inhibitor for at least 12 weeks. Patients in treatment with anti-A $\beta$ or anti-tau protein, vaccine with live/live-attenuated bacterial or virus in the latest 3 months, immunosuppressant and corticosteroids in the latest 2 months, anticoagulant, estrogens have been excluded, as well as patients with $\mathrm{HCV}, \mathrm{HBV}$, HIV infections or malignancy in the previous 2 years. The primary endpoint is an improvement of at least 4 points at ADAS-cog/11 after 24 weeks of treatment. Secondary endpoints include unchanging or improvement at ADAS-cog/12, MMSE, CDR-SB, ADCOMS after 24 weeks of treatment from baseline. Adverse and serious adverse effects will be assessed after 35 weeks from initial treatment. Study is estimated to be completed within the end of 2021.

\section{Rapamycin (NCT04200911)}

In light of preclinical evidence, rapamycin is an effective inhibitor of AD-related neurodegeneration (Cai et al., 2012). The most important suggested mechanisms include enhancement of autophagy and the consequent increase of the clearance of A $\beta$ aggregates (Santos et al., 2011), and attenuation of tau hyperphosphorylation (Liu et al., 2013).

The combination of these elements supported the running of the study Cognition, Age, and RaPamycin

TABLE 1 | Ongoing clinical trials that use the drug-repositioning method for drug discovery of AD.

\begin{tabular}{|c|c|c|c|c|c|c|}
\hline Drug & Phase & Duration & $\begin{array}{c}\text { Number of } \\
\text { patients }\end{array}$ & Official Title & Primary Outcome Measures & $\begin{array}{l}\text { ClinicalTrials.gov } \\
\text { Identifier }\end{array}$ \\
\hline Daratumumab & Phase 2 & 24 weeks & 15 & $\begin{array}{l}\text { An Open-Label, Pilot Study of } \\
\text { Daratumumab SC in Patients With Mild to } \\
\text { Moderate Alzheimer's Disease (DARZAD) }\end{array}$ & $\begin{array}{l}\text { ADAS-cog/ } 11 \text { [Time Frame: } 25 \text { weeks] } \\
\text { Responder rate defined as } \\
\text { improvement of } \geq 4 \text { points on standard } \\
\text { 11-item. }\end{array}$ & NCT04070378 \\
\hline Rapamycin & Phase 1 & 8 weeks & 10 & $\begin{array}{l}\text { Cognition, Age, and Rapamycin } \\
\text { Effectiveness Downregulation of the } \\
m \text {-Tor Pathway (CARPE DIEM) }\end{array}$ & $\begin{array}{l}\text { Blood brain barrier penetration of RAPA } \\
\text { [Time Frame: Change from Baseline to } \\
8 \text { weeks] }\end{array}$ & NCT04200911 \\
\hline Lenalidomide & Phase 2 & 18 month & 30 & $\begin{array}{l}\text { MCLENA-1: A Phase // Clinical Trial for the } \\
\text { Assessment of Safety, Tolerability, and } \\
\text { Efficacy of Lenalidomide in Patients With } \\
\text { Mild Cognitive Impairment Due to } \\
\text { Alzheimer's Disease }\end{array}$ & $\begin{array}{l}\text { Change in cognition as assessed by the } \\
\text { Alzheimer's Disease Assessment } \\
\text { Scale-Cognitive Subscale (ADAS-Cog) } \\
\text { total score [Time Frame: } 18 \text { months] }\end{array}$ & NCT04032626 \\
\hline Tacrolimus & Phase 2 & 12 weeks & 12 & $\begin{array}{l}\text { A Pilot Open Labeled Study of Tacrolimus } \\
\text { to Assess its Effects on Bio-markers of } \\
\text { Mild Cognitive Impairment and } \\
\text { Alzheimer's Disease }\end{array}$ & $\begin{array}{l}\text { CSF biomarkers of target engagement, } \\
\text { AD pathology, and neurodegeneration } \\
\text { [Time Frame: Baseline and } 12 \text { weeks] }\end{array}$ & NCT04263519 \\
\hline XPro1595 & Phase 1 & 12 weeks & 18 & $\begin{array}{l}\text { Phase } 1 \text { b Open-Label, Dose-Identification } \\
\text { Study of XPro1595 in Patients With Mild } \\
\text { to Moderate Alzheimer's Disease With } \\
\text { Elevated High Sensitivity C-reactive } \\
\text { Protein in Blood }\end{array}$ & $\begin{array}{l}\text { The number and percentage of patients } \\
\text { with a treatment-emergent adverse } \\
\text { event throughout } 12 \text { weeks of } \\
\text { treatment with XPro1595 }\end{array}$ & NCT03943264 \\
\hline
\end{tabular}


Effectiveness-DownregulatIon of the mTOR-pathway (CARPE $D I E M)$, an early phase 1 clinical trial, involving 10 patients, in a single group, finalized to evaluate the effect of oral Rapamycin in older adults with $\mathrm{AD}$ and mild cognitive impairment (MCI). It represents an open-label pilot study that, once established the feasibility and safety of the treatment, should constitute an initial proof-of-concept for a larger Phase 2 clinical trial.

In this study, Sirolimus $1 \mathrm{mg}$ has been administered per os once a day for 8 weeks. The primary endpoint measures the penetration of Rapamycin across BBB, by means of lumbar puncture at baseline and after the final dose, while the secondary endpoints include changes in $\mathrm{AD}$ progression through evaluation of $\mathrm{AD}$ biomarkers, as well as cognitive and physical tests.

The 10 patients recruited, between 55 and 85 years, present a diagnosis of MCI, Clinical Dementia Rating Scale between 0.5 and 1 , HVLT-R $<5 \%$ and normal blood cell counts. Patients must also be on a stable dose of $\mathrm{AD}$ medication since at least 3 months.

People with diabetes, with a history of skin ulcers, in therapy with anti-platelet agents, anti-coagulant medications or other drugs affecting cytochrome CYP3A4, have been excluded. Furthermore, people with recent history of cardiovascular, major disorders, significant neurological disorders, active inflammatory, autoimmune, infectious, hepatic, malignant or psychiatric disease have been cut off. The primary completion date is estimated for July 2021. This study could be the first approach to a phase 2 clinical trial of rapamycin.

\section{Lenalidomide (NCT04032626)}

Lenalidomide, used for multiple myeloma and myelodysplastic syndromes, acts as immunomodulator, anti-cancer and antiangiogenic drug (Quach et al., 2010). The pleiotropic antiinflammatory activity of the drug, combined with evidence from previous clinical trials with thalidomide, led to the construction of the study MCLENA-1 (Decourt et al., 2020) a clinical trial for the assessment of Lenalidomide in patients with MCI. The investigators designed an 18-month, Phase II, double-blind, randomized, two-armed, parallel group, placebo controlled clinical trial aimed to test the hypothesis that lenalidomide reduces inflammatory and $\mathrm{AD}$-associated pathological biomarkers, thus improving cognition. Estimated enrollment counts of 30 participants, aged between 50 and 90 years with MCI diagnosed, that have been randomized into two arms: one with lenalidomide $(10 \mathrm{mg} /$ day orally administered for 12 months followed by 6 months of washout) and one with placebo (orally administered for 12 months followed by 6 months of washout).

Primary endpoints will evaluate the change in cognition by ADAS-Cog, ADCS-ADL, CDR-SOB, MMSE. Secondary endpoints include the AEs assessment and blood toxicity in terms of platelets falling below $50000 / \mu \mathrm{L}$ and neutrophils falling below $1000 / \mu \mathrm{L}$. The effects on amyloid loads, CNS neurodegeneration and on blood inflammatory markers will also be assessed.

Investigators expect to first complete within September 2023. Estimated study completion date is on September 2024.

\section{Tacrolimus (NCT04263519)}

Recent studies, which suggest a protective action of tacrolimus in countering the synaptotoxic cascade associated with $A \beta$ (O'Neal et al., 2018), represent the basis of a phase 2, pilot, open labeled study, aimed to investigate the neurobiological effect of tacrolimus in subjects with MCI and AD-related dementia. The twelve patients enrolled have been randomized into two arms, in which, a different concentration of the drug will be collected (2-5 ng/ml vs. $5.1-10 \mathrm{ng} / \mathrm{ml})$. Primary endpoint includes the effects of tacrolimus on CSF biomarkers (IL-2, IL-6, INF $\beta$, YKL-40), deposition of $A \beta$, p-tau, and neurodegeneration. Parameters will be assessed at baseline and after 12 weeks of treatment. Effects on structural neuroimaging (MRI), electroencephalograms (EEG), on cognitive functions assessed by different inventory (MoCA, NPIQ, FAQ) will be explored as secondary outcomes. The study is planned to be completed within December 2021.

\section{XPro1595 (NCT03943264)}

Preclinical studies have shown that selective anti-TNF biologic, XPro1595, ameliorates neurologic dysfunction in mouse models of amyloid pathology (MacPherson et al., 2017).

On the basis of such preclinical evidence, in June 2019, a multicentre phase $1 \mathrm{~b}$ open-label trial aimed to determine the safety, tolerability, and efficacy of XPro1595 in 18 patients with mild to moderate $\mathrm{AD}$ and evidence of peripheral inflammation by way of elevated blood C-reactive protein has got started. Participants have received weekly injections of $0.03,1.0$, or $3.0 \mathrm{mg} / \mathrm{kg}$ XPro1595 for 12 weeks. The primary endpoint is safety, while secondary endpoints include change from baseline in biomarkers of neuroinflammation, such as blood and CSF C-reactive protein, TNF- $\alpha$, interleukin-1, and interleukin-6. CSF, $A \beta$ and tau, and cognitive and psychiatric endpoints will also be measured. The estimated study completion date is December 2020.

\section{CONCLUSION}

The clinical experience gained in the arena of pharmacological treatment of inflammatory diseases represents a remarkable source of potential candidates to treat diseases with high unmet clinical need, such as $\mathrm{AD}$, which may achieve considerable benefits from advantageously repositioning an array of pharmacological agents with known safety profile. Thus, unraveling inflammatory aspects of $\mathrm{AD}$ and compare them to mechanisms already known in other inflammatory disorders, becomes of primary relevance to reduce the disease burden in one of the most diffused dementia. In addition, the growingly shared perspective that $\mathrm{AD}$ not only involves activation of the immune/inflammatory response in the brain, but also depends upon peripheral immunological disturbances, helps to strengthen the concept that some of the immunomodulating drugs commonly used in inflammatory and/or proliferative diseases, might contribute to achieve meaningful clinical benefits also in $\mathrm{AD}$ patients. For these reasons, drug repositioning represents an appealing choice for diseases with poor therapeutic 
options, with the further advantage of conveniently reduced research and development costs, with special regard to clinical trials.

To date, there are no disease-modifying therapies available for $\mathrm{AD}$, and the main goals of actually active trials are to detect the stage of $\mathrm{AD}$ at which the treatment should be more appropriately initiated, along with a durability of the treatment itself that would prevent patients from undergoing cognitive decline progression (if at all). In a clearer preclinical scenario which offers an increasing array of immune/inflammatory targets in the brain and in periphery and considering the quite wide panel of drugs which may interfere with these mechanisms, in analogy with their approved use in peripheral immune disorders, an innovative, disease modifying, treatment option(s) for $\mathrm{AD}$ may not be far away from the patient's bedside.

\section{REFERENCES}

Ali, M. M., Ghouri, R. G., Ans, A. H., Akbar, A., and Toheed, A. (2019). Recommendations for anti-inflammatory treatments in Alzheimer's disease: a comprehensive review of the literature. Cureus 11:e4620. doi: 10.7759/cureus. 4620

Anwar, S., and Rivest, S. (2020). Alzheimer's disease: microglia targets and their modulation to promote amyloid phagocytosis and mitigate neuroinflammation. Expert. Opin. Ther. Targets 24, 331-344. doi: 10.1080/14728222.2020.1738391

Ardura-Fabregat, A., Boddeke, E. W. G. M., Boza-Serrano, A., Brioschi, S., Castro-Gomez, S., Ceyzériat, K., et al. (2017). Targeting neuroinflammation to treat Alzheimer's disease. CNS Drugs 31, 1057-1082. doi: 10.1007/s40263-0170483-3

Arnon, R., and Aharoni, R. (2019). Glatiramer acetate: from bench to bed and back. Isr. Med. Assoc. J. 21, 151-157.

Bakalash, S., Pham, M., Koronyo, Y., Salumbides, B. C., Kramerov, A., Seidenberg, H., et al. (2011). Egrl expression is induced following glatiramer acetate immunotherapy in rodent models of glaucoma and Alzheimer's disease. Invest. Ophthalmol. Vis. Sci. 52, 9033-9046. doi: 10.1167/iovs.11-7498

Baruch, K., Deczkowska, A., Rosenzweig, N., Tsitsou-Kampeli, A., Sharif, A. M., Matcovitch-Natan, O., et al. (2016). PD-1 immune checkpoint blockade reduces pathology and improves memory in mouse models of Alzheimer's disease. Nat. Med. 22, 135-137. doi: 10.1038/nm.4022

Baruch, K., Rosenzweig, N., Kertser, A., Deczkowska, A., Sharif, A. M., Spinrad, A., et al. (2015). Breaking immune tolerance by targeting Foxp3(+) regulatory T cells mitigates Alzheimer's disease pathology. Nat. Commun. 6:7967. doi: 10.1038/ncomms8967

Bascones-Martinez, A., Mattila, R., Gomez-Font, R., and Meurman, J. H. (2014). Immunomodulatory drugs: oral and systemic adverse effects. Med. Oral Patol. Oral Circ. Bucal. 19, e24-e31. doi: 10.4317/medoral.19087

Belarbi, K., Jopson, T., Tweedie, D., Arellano, C., Luo, W., Greig, N. H., et al. (2012). TNF- $\alpha$ protein synthesis inhibitor restores neuronal function and reverses cognitive deficits induced by chronic neuroinflammation. J. Neuroinflamm. 9:23. doi: 10.1186/1742-2094-9-23

Biscaro, B., Lindvall, O., Tesco, G., Ekdahl, C. T., and Nitsch, R. M. (2012). Inhibition of microglial activation protects hippocampal neurogenesis and improves cognitive deficits in a transgenic mouse model for Alzheimer's disease. Neurodegener. Dis. 9, 187-198. doi: 10.1159/000330363

Blacher, E., Dadali, T., Bespalko, A., Haupenthal, V. J., Grimm, M. O. W., Hartmann, T., et al. (2015). Alzheimer's disease pathology is attenuated in a CD38-deficient mouse model. Ann. Neurol. 78, 88-103. doi: 10.1002/ana.24425

Bronzuoli, M. R., Iacomino, A., Steardo, L., and Scuderi, C. (2016). Targeting neuroinflammation in Alzheimer's disease. J. Inflamm. Res. 9, 199-208. doi: 10.2147/JIR.S86958

Bulk, M., Kenkhuis, B., van der Graaf, L. M., Goeman, J. J., Natté, R., and van der Weerd, L. (2018). Postmortem T2*- weighted MRI imaging of cortical iron reflects severity of Alzheimer's disease. J. Alzheimers Dis. 65, 1125-1137. doi: 10.3233/JAD-180317

\section{AUTHOR CONTRIBUTIONS}

$\mathrm{AM}$ and $\mathrm{CB}$ drafted and edited the manuscript and prepared figures and table. GD performed literature searching and drafted the manuscript. $\mathrm{MD}$ and $\mathrm{RD}$ performed searching of clinical trials. RB critically reviewed and edited the manuscript. GC conceived the idea of this review and edited the manuscript. All authors contributed to the article and approved the submitted version.

\section{FUNDING}

The work has been funded by the PRIN grant no. 2017YH3SXK from the Italian Ministry of Research.

Burgaletto, C., Munafò, A., Di Benedetto, G., De Francisci, C., Caraci, F., Di Mauro, R., et al. (2020). The immune system on the TRAIL of Alzheimer's disease. J. Neuroinflamm. 17:298. doi: 10.1186/s12974-020-01968-1

Butchart, J., Brook, L., Hopkins, V., Teeling, J., Püntener, U., Culliford, D., et al. (2015). Etanercept in Alzheimer disease. Neurology 84, 2161-2168. doi: 10.1212/ WNL.0000000000001617

Butovsky, O., Koronyo-Hamaoui, M., Kunis, G., Ophir, E., Landa, G., Cohen, H., et al. (2006). Glatiramer acetate fights against Alzheimer's disease by inducing dendritic-like microglia expressing insulin-like growth factor 1. Proc. Natl. Acad. Sci. U.S.A. 103, 11784-11789. doi: 10.1073/pnas.0604681103

Caccamo, A., Majumder, S., Richardson, A., Strong, R., and Oddo, S. (2010). Molecular interplay between mammalian target of rapamycin (mTOR), amyloid-beta, and Tau: effects on cognitive impairments. J. Biol. Chem. 285, 13107-13120. doi: 10.1074/jbc.M110.100420

Cai, Z., Zhao, B., Li, K., Zhang, L., Li, C., Quazi, S. H., et al. (2012). Mammalian target of rapamycin: a valid therapeutic target through the autophagy pathway for Alzheimer's disease? J. Neurosci. Res. 90, 1105-1118. doi: 10.1002/jnr. 23011

Cantarella, G., Di Benedetto, G., Puzzo, D., Privitera, L., Loreto, C., Saccone, S., et al. (2015). Neutralization of TNFSF10 ameliorates functional outcome in a murine model of Alzheimer's disease. Brain 138, 203-216. doi: 10.1093/brain/ awu318

Cantarella, G., Uberti, D., Carsana, T., Lombardo, G., Bernardini, R., and Memo, M. (2003). Neutralization of TRAIL death pathway protects human neuronal cell line from beta-amyloid toxicity. Cell Death Differ. 10, 134-141. doi: 10.1038/ sj.cdd. 4401143

Castellani, G., and Schwartz, M. (2020). Immunological features of non-neuronal brain cells: implications for Alzheimer's disease immunotherapy. Trends Immunol. 41, 794-804. doi: 10.1016/j.it.2020.07.005

Cavanagh, C., Tse, Y. C., Nguyen, H.-B., Krantic, S., Breitner, J. C. S., Quirion, R., et al. (2016). Inhibiting tumor necrosis factor- $\alpha$ before amyloidosis prevents synaptic deficits in an Alzheimer's disease model. Neurobiol. Aging 47, 41-49. doi: 10.1016/j.neurobiolaging.2016.07.009

Chakraborty, S., Kaushik, D. K., Gupta, M., and Basu, A. (2010). Inflammasome signaling at the heart of central nervous system pathology. J. Neurosci. Res. 88, 1615-1631. doi: 10.1002/jnr.22343

Chamoto, K., Al-Habsi, M., and Honjo, T. (2017). Role of PD-1 in immunity and diseases. Curr. Top. Microbiol. Immunol. 410, 75-97. doi: 10.1007/82_2017_67

Chang, R., Yee, K.-L., and Sumbria, R. K. (2017). Tumor necrosis factor $\alpha$ inhibition for Alzheimer's disease. J. Cent. Nerv. Syst. Dis. 9:1179573517709278.

Chen, L., Yao, Y., Wei, C., Sun, Y., Ma, X., Zhang, R., et al. (2015). T cell immunity to glatiramer acetate ameliorates cognitive deficits induced by chronic cerebral hypoperfusion by modulating the microenvironment. Sci. Rep. 5:14308. doi: 10.1038/srep14308

Choi, Y., Kim, H.-S., Shin, K. Y., Kim, E.-M., Kim, M., Kim, H.-S., et al. (2007). Minocycline attenuates neuronal cell death and improves cognitive impairment in Alzheimer's disease models. Neuropsychopharmacology 32, 2393-2404. doi: 10.1038/sj.npp.1301377 
Citron, M. (2010). Alzheimer's disease: strategies for disease modification. Nat. Rev. Drug Discov. 9, 387-398. doi: 10.1038/nrd2896

Cummings, J., Aisen, P. S., DuBois, B., Frölich, L., Jack, C. R., Jones, R. W., et al. (2016). Drug development in Alzheimer's disease: the path to 2025. Alzheimers Res. Ther. 8:39. doi: 10.1186/s13195-016-0207-9

Cummings, J., Lee, G., Ritter, A., Sabbagh, M., and Zhong, K. (2020). Alzheimer's disease drug development pipeline: 2020. Alzheimers Dement. 6:e12050. doi: $10.1002 / \operatorname{trc} 2.12050$

Curdy, N., Lanvin, O., Laurent, C., Fournié, J.-J., and Franchini, D.-M. (2019). Regulatory mechanisms of inhibitory immune checkpoint receptors expression. Trends Cell Biol. 29, 777-790. doi: 10.1016/j.tcb.2019.07.002

Darvin, P., Toor, S. M., Sasidharan Nair, V., and Elkord, E. (2018). Immune checkpoint inhibitors: recent progress and potential biomarkers. Exp. Mol. Med. 50, 1-11. doi: 10.1038/s12276-018-0191-1

Decourt, B., Drumm-Gurnee, D., Wilson, J., Jacobson, S., Belden, C., Sirrel, S., et al. (2017). Poor safety and tolerability hamper reaching a potentially therapeutic dose in the use of thalidomide for Alzheimer's disease: results from a doubleblind, placebo-controlled trial. Curr. Alzheimer Res. 14, 403-411. doi: 10.2174/ 1567205014666170117141330

Decourt, B., Wilson, J., Ritter, A., Dardis, C., Difilippo, F. P., Zhuang, X., et al. (2020). MCLENA-1: a phase II clinical trial for the assessment of safety, tolerability, and efficacy of Lenalidomide in patients with mild cognitive impairment due to Alzheimer's disease. Open Access. J. Clin. Trials 12, 1-13. doi: $10.2147 /$ oajct.s221914

Detrait, E. R., Danis, B., Lamberty, Y., and Foerch, P. (2014). Peripheral administration of an anti-TNF- $\alpha$ receptor fusion protein counteracts the amyloid induced elevation of hippocampal TNF- $\alpha$ levels and memory deficits in mice. Neurochem. Int. 72, 10-13. doi: 10.1016/j.neuint.2014.04.001

Di Benedetto, G., Burgaletto, C., Carta, A. R., Saccone, S., Lempereur, L., Mulas, G., et al. (2019). Beneficial effects of curtailing immune susceptibility in an Alzheimer's disease model. J. Neuroinflamm. 16:166. doi: 10.1186/s12974-0191554-9

Edler, M. K., Sherwood, C. C., Meindl, R. S., Hopkins, W. D., Ely, J. J., Erwin, J. M., et al. (2017). Aged chimpanzees exhibit pathologic hallmarks of Alzheimer's disease. Neurobiol. Aging 59, 107-120. doi: 10.1016/j.neurobiolaging.2017. 07.006

Familian, A., Boshuizen, R. S., Eikelenboom, P., and Veerhuis, R. (2006). Inhibitory effect of minocycline on amyloid beta fibril formation and human microglial activation. Glia 53, 233-240. doi: 10.1002/glia.20268

Fan, R., Xu, F., Previti, M. L., Davis, J., Grande, A. M., Robinson, J. K., et al. (2007). Minocycline reduces microglial activation and improves behavioral deficits in a transgenic model of cerebral microvascular amyloid. J. Neurosci. 27, 3057-3063. doi: 10.1523/JNEUROSCI.4371-06.2007

Ferretti, M. T., Allard, S., Partridge, V., Ducatenzeiler, A., and Cuello, A. C. (2012). Minocycline corrects early, pre-plaque neuroinflammation and inhibits BACE-1 in a transgenic model of Alzheimer's disease-like amyloid pathology. J. Neuroinflamm. 9:62. doi: 10.1186/1742-2094-9-62

Filiano, A. J., Xu, Y., Tustison, N. J., Marsh, R. L., Baker, W., Smirnov, I., et al. (2016). Unexpected role of interferon- $\gamma$ in regulating neuronal connectivity and social behaviour. Nature 535, 425-429. doi: 10.1038/nature18626

Fischer, P., Zehetmayer, S., Jungwirth, S., Weissgram, S., Krampla, W., Hinterberger, M., et al. (2008). Risk factors for Alzheimer dementia in a community-based birth cohort at the age of 75 years. Dement. Geriatr. Cogn. Disord. 25, 501-507. doi: 10.1159/000128577

Frenkel, D., Maron, R., Burt, D. S., and Weiner, H. L. (2005). Nasal vaccination with a proteosome-based adjuvant and glatiramer acetate clears beta-amyloid in a mouse model of Alzheimer disease. J. Clin. Invest. 115, 2423-2433. doi: $10.1172 /$ JCI23241

Fu, W.-Y., Wang, X., and Ip, N. Y. (2019). Targeting Neuroinflammation as a therapeutic strategy for Alzheimer's disease: mechanisms, drug candidates, and new opportunities. ACS Chem. Neurosci. 10, 872-879. doi: 10.1021/ acschemneuro.8b00402

Gabbita, S. P., Srivastava, M. K., Eslami, P., Johnson, M. F., Kobritz, N. K., Tweedie, D., et al. (2012). Early intervention with a small molecule inhibitor for tumor necrosis factor- $\alpha$ prevents cognitive deficits in a triple transgenic mouse model of Alzheimer's disease. J. Neuroinflamm. 9:99. doi: 10.1186/1742-2094-9-99

Garrido-Mesa, N., Zarzuelo, A., and Gálvez, J. (2013). Minocycline: far beyond an antibiotic. Br. J. Pharmacol. 169, 337-352. doi: 10.1111/bph.12139
Gate, D., Saligrama, N., Leventhal, O., Yang, A. C., Unger, M. S., Middeldorp, J., et al. (2020). Clonally expanded CD8 T cells patrol the cerebrospinal fluid in Alzheimer's disease. Nature 577, 399-404. doi: 10.1038/s41586-0191895-7

Giuliani, F., Vernay, A., Leuba, G., and Schenk, F. (2009). Decreased behavioral impairments in an Alzheimer mice model by interfering with TNF-alpha metabolism. Brain Res. Bull. 80, 302-308. doi: 10.1016/j.brainresbull.2009. 07.009

Griffin, W. S. T. (2013). Neuroinflammatory cytokine signaling and Alzheimer's disease. N. Engl. J. Med. 368, 770-771. doi: 10.1056/NEJMcibr1214546

Guerreiro, S., Privat, A.-L., Bressac, L., and Toulorge, D. (2020). CD38 in neurodegeneration and neuroinflammation. Cells 9:471. doi: 10.3390/ cells 9020471

Gureev, A. P., Popov, V. N., and Starkov, A. A. (2020). Crosstalk between the mTOR and Nrf2/ARE signaling pathways as a target in the improvement of long-term potentiation. Exper. Neurol. 328:113285. doi: 10.1016/j.expneurol.2020.113285

Haam, J., and Yakel, J. L. (2017). Cholinergic modulation of the hippocampal region and memory function. J. Neurochem. 142(Suppl. 2), 111-121. doi: 10.1111/jnc. 14052

Hardy, J., and Selkoe, D. J. (2002). The amyloid hypothesis of Alzheimer's disease: progress and problems on the road to therapeutics. Science 297, 353-356. doi: $10.1126 /$ science. 1072994

Havel, J. J., Chowell, D., and Chan, T. A. (2019). The evolving landscape of biomarkers for checkpoint inhibitor immunotherapy. Nat. Rev. Cancer 19, 133-150. doi: 10.1038/s41568-019-0116-x

He, P., Cheng, X., Staufenbiel, M., Li, R., and Shen, Y. (2013). Long-term treatment of thalidomide ameliorates amyloid-like pathology through inhibition of $\beta$ secretase in a mouse model of Alzheimer's disease. PLoS One 8:e55091. doi: 10.1371/journal.pone.0055091

Heinz, S., Benner, C., Spann, N., Bertolino, E., Lin, Y. C., Laslo, P., et al. (2010). Simple combinations of lineage-determining transcription factors prime cisregulatory elements required for macrophage and B cell identities. Mol. Cell 38, 576-589. doi: 10.1016/j.molcel.2010.05.004

Heneka, M. T., Golenbock, D. T., and Latz, E. (2015). Innate immunity in Alzheimer's disease. Nat. Immunol. 16, 229-236. doi: 10.1038/ni.3102

Houck, A. L., Seddighi, S., and Driver, J. A. (2018). At the crossroads between neurodegeneration and cancer: a review of overlapping biology and its implications. Curr. Aging Sci. 11, 77-89. doi: 10.2174/18746098116661802 23154436

Ihara, M., and Saito, S. (2020). Drug repositioning for Alzheimer's disease: finding hidden clues in old drugs. J. Alzheimers Dis. 74, 1013-1028. doi: 10.3233/JAD200049

Jiang, T., Yu, J.-T., Zhu, X.-C., Tan, M.-S., Wang, H.-F., Cao, L., et al. (2014). Temsirolimus promotes autophagic clearance of amyloid- $\beta$ and provides protective effects in cellular and animal models of Alzheimer's disease. Pharmacol. Res. 81, 54-63. doi: 10.1016/j.phrs.2014.02.008

Jung, Y. J., Tweedie, D., Scerba, M. T., and Greig, N. H. (2019). Neuroinflammation as a factor of neurodegenerative disease: thalidomide analogs as treatments. Front. Cell Dev. Biol. 7:313. doi: 10.3389/fcell.2019.00313

Kaeberlein, M., and Galvan, V. (2019). Rapamycin and Alzheimer's disease: time for a clinical trial? Sci. Transl. Med. 11:eaar4289. doi: 10.1126/scitranslmed. aar4289

Khanna, A. K. (2000). Mechanism of the combination immunosuppressive effects of rapamycin with either cyclosporine or tacrolimus. Transplantation 70, 690694. doi: 10.1097/00007890-200008270-00027

Kim, D. H., Choi, S.-M., Jho, J., Park, M.-S., Kang, J., Park, S. J., et al. (2016). Infliximab ameliorates $\mathrm{AD}$-associated object recognition memory impairment. Behav. Brain Res. 311, 384-391. doi: 10.1016/j.bbr.2016.06.001

Kipnis, J., Cohen, H., Cardon, M., Ziv, Y., and Schwartz, M. (2004). T cell deficiency leads to cognitive dysfunction: implications for therapeutic vaccination for schizophrenia and other psychiatric conditions. Proc. Natl. Acad. Sci. U.S.A. 101, 8180-8185. doi: 10.1073/pnas.0402268101

Kiyota, T., Machhi, J., Lu, Y., Dyavarshetty, B., Nemati, M., Yokoyama, I., et al. (2018). Granulocyte-macrophage colony-stimulating factor neuroprotective activities in Alzheimer's disease mice. J. Neuroimmunol. 319, 80-92. doi: 10. 1016/j.jneuroim.2018.03.009

Koronyo, Y., Salumbides, B. C., Sheyn, J., Pelissier, L., Li, S., Ljubimov, V. et al. (2015). Therapeutic effects of glatiramer acetate and grafted CD115+ 
monocytes in a mouse model of Alzheimer's disease. Brain 138, 2399-2422. doi: 10.1093/brain/awv150

Kou, W., Banerjee, S., Eudy, J., Smith, L. M., Persidsky, R., Borgmann, K., et al. (2009). CD38 regulation in activated astrocytes: implications for neuroinflammation and HIV-1 brain infection. J. Neurosci. Res. 87, 2326-2339. doi: 10.1002/jnr.22060

Kübra Elçioğlu, H., Kabasakal, L., Tufan, F., Elçioğlu, ÖH., Solakoglu, S., Kotil, T., et al. (2015). Effects of systemic thalidomide and intracerebroventricular etanercept and infliximab administration in a Streptozotocin induced dementia model in rats. Acta Histochem. 117, 176-181. doi: 10.1016/j.acthis.2014.12.002

Kumar, A., and Singh, N. (2017). Calcineurin inhibitors improve memory loss and neuropathological changes in mouse model of dementia. Pharmacol. Biochem. Behav. 153, 147-159. doi: 10.1016/j.pbb.2016.12.018

Kunkle, B. W., Grenier-Boley, B., Sims, R., Bis, J. C., Damotte, V., Naj, A. C., et al. (2019). Genetic meta-analysis of diagnosed Alzheimer's disease identifies new risk loci and implicates $\mathrm{A} \beta$, tau, immunity and lipid processing. Nat. Genet. 51 , 414-430. doi: 10.1038/s41588-019-0358-2

Lalive, P. H., Neuhaus, O., Benkhoucha, M., Burger, D., Hohlfeld, R., Zamvil, S. S., et al. (2011). Glatiramer acetate in the treatment of multiple sclerosis: emerging concepts regarding its mechanism of action. CNS Drugs 25, 401-414. doi: 10.2165/11588120-000000000-00000

Lapadula, G., Marchesoni, A., Armuzzi, A., Blandizzi, C., Caporali, R., Chimenti, S., et al. (2014). Adalimumab in the treatment of immune-mediated diseases. Int. J. Immunopathol. Pharmacol. 27, 33-48. doi: 10.1177/03946320140270S103

Latta-Mahieu, M., Elmer, B., Bretteville, A., Wang, Y., Lopez-Grancha, M., Goniot, P., et al. (2018). Systemic immune-checkpoint blockade with antiPD1 antibodies does not alter cerebral amyloid- $\beta$ burden in several amyloid transgenic mouse models. Glia 66, 492-504. doi: 10.1002/glia.23260

Law, B. K. (2005). Rapamycin: an anti-cancer immunosuppressant? Crit. Rev. Oncol. Hematol. 56, 47-60. doi: 10.1016/j.critrevonc.2004.09.009

Lee, R. K., Knapp, S., and Wurtman, R. J. (1999). Prostaglandin E2 stimulates amyloid precursor protein gene expression: inhibition by immunosuppressants. J. Neurosci. 19, 940-947. doi: 10.1523/jneurosci.19-03-00940.1999

Lesokhin, A. M., Callahan, M. K., Postow, M. A., and Wolchok, J. D. (2015). On being less tolerant: enhanced cancer immunosurveillance enabled by targeting checkpoints and agonists of T cell activation. Sci. Transl. Med. 7:280sr1. doi: 10.1126/scitranslmed.3010274

Li, S., Hayden, E. Y., Garcia, V. J., Fuchs, D.-T., Sheyn, J., Daley, D. A., et al. (2020). Activated bone marrow-derived macrophages eradicate Alzheimer'srelated A $\beta 42$ Oligomers and protect synapses. Front. Immunol. 11:49. doi: 10.3389/fimmu.2020.00049

Lin, A.-L., Zheng, W., Halloran, J. J., Burbank, R. R., Hussong, S. A., Hart, M. J., et al. (2013). Chronic rapamycin restores brain vascular integrity and function through NO synthase activation and improves memory in symptomatic mice modeling Alzheimer's disease. J. Cereb. Blood Flow Metab. 33, 1412-1421. doi: 10.1038/jcbfm.2013.82

Lin, C.-T., Lecca, D., Yang, L.-Y., Luo, W., Scerba, M. T., Tweedie, D., et al. (2020). 3,6'-dithiopomalidomide reduces neural loss, inflammation, behavioral deficits in brain injury and microglial activation. eLife 9:e54726. doi: 10.7554/eLife. 54726

Liu, Y., Su, Y., Wang, J., Sun, S., Wang, T., Qiao, X., et al. (2013). Rapamycin decreases tau phosphorylation at Ser214 through regulation of cAMPdependent kinase. Neurochem. Int. 62, 458-467. doi: 10.1016/j.neuint.2013. 01.014

Lo, A. W., Ho, C., Cummings, J., and Kosik, K. S. (2014). Parallel discovery of Alzheimer's therapeutics. Sci. Transl. Med. 6:241cm5. doi: 10.1126/ scitranslmed.3008228

MacPherson, K. P., Sompol, P., Kannarkat, G. T., Chang, J., Sniffen, L., Wildner, M. E., et al. (2017). Peripheral administration of the soluble TNF inhibitor XPro1595 modifies brain immune cell profiles, decreases beta-amyloid plaque load, and rescues impaired long-term potentiation in 5xFAD mice. Neurobiol. Dis. 102, 81-95. doi: 10.1016/j.nbd.2017.02.010

Majumder, S., Richardson, A., Strong, R., and Oddo, S. (2011). Inducing autophagy by rapamycin before, but not after, the formation of plaques and tangles ameliorates cognitive deficits. PLoS One 6:e25416. doi: 10.1371/journal.pone. 0025416

McAlpine, F. E., Lee, J.-K., Harms, A. S., Ruhn, K. A., Blurton-Jones, M., Hong, J., et al. (2009). Inhibition of soluble TNF signaling in a mouse model of
Alzheimer's disease prevents pre-plaque amyloid-associated neuropathology. Neurobiol. Dis. 34, 163-177. doi: 10.1016/j.nbd.2009.01.006

Melsheimer, R., Geldhof, A., Apaolaza, I., and Schaible, T. (2019). Remicade ${ }^{\circledR}$ (infliximab): 20 years of contributions to science and medicine. Biologics 13, 139-178. doi: 10.2147/BTT.S207246

Monacelli, F., Cea, M., Borghi, R., Odetti, P., and Nencioni, A. (2017). Do cancer drugs counteract neurodegeneration? repurposing for Alzheimer's disease. J. Alzheimers Dis. 55, 1295-1306. doi: 10.3233/JAD- 160840

Ní Chasaide, C., and Lynch, M. A. (2020). The role of the immune system in driving neuroinflammation. Brain Neurosci. Adv. 4:2398212819901082. doi: $10.1177 / 2398212819901082$

Obst, J., Mancuso, R., Simon, E., and Gomez-Nicola, D. (2018). PD-1 deficiency is not sufficient to induce myeloid mobilization to the brain or alter the inflammatory profile during chronic neurodegeneration. Brain Behav. Immun. 73, 708-716. doi: 10.1016/j.bbi.2018.08.006

Okereke, O. I., and Meadows, M.-E. (2019). More evidence of an inverse association between cancer and Alzheimer disease. JAMA Netw. Open 2:e196167. doi: 10.1001/jamanetworkopen.2019.6167

Olmos, G., and Lladó, J. (2014). Tumor necrosis factor alpha: a link between neuroinflammation and excitotoxicity. Med. Inflamm. 2014:861231. doi: 10. $1155 / 2014 / 861231$

O’Neal, M. A., Stallings, N. R., and Malter, J. S. (2018). Alzheimer's disease, dendritic spines, and calcineurin inhibitors: a new approach? ACS Chem. Neurosci. 9, 1233-1234. doi: 10.1021/acschemneuro.8b00213

Paouri, E., and Georgopoulos, S. (2019). Systemic and CNS inflammation crosstalk: implications for Alzheimer's disease. Curr. Alzheimer Res. 16, 559-574. doi: $10.2174 / 1567205016666190321154618$

Paouri, E., Tzara, O., Kartalou, G.-I., Zenelak, S., and Georgopoulos, S. (2017). Peripheral tumor necrosis factor-Alpha (TNF- $\alpha$ ) modulates Amyloid pathology by regulating blood-derived immune cells and glial response in the brain of AD/TNF transgenic mice. J. Neurosci. 37, 5155-5171. doi: 10.1523/ JNEUROSCI.2484-16.2017

Park, J., Lee, S.-Y., Shon, J., Kim, K., Lee, H. J., Kim, K. A., et al. (2019). Adalimumab improves cognitive impairment, exerts neuroprotective effects and attenuates neuroinflammation in an A $\beta 1-40$-injected mouse model of Alzheimer's disease. Cytotherapy 21, 671-682. doi: 10.1016/j.jcyt.2019. 04.054

Perry, V. H., Nicoll, J. A. R., and Holmes, C. (2010). Microglia in neurodegenerative disease. Nat. Rev. Neurol. 6, 193-201. doi: 10.1038/nrneurol.2010.17

Pillaiyar, T., Meenakshisundaram, S., Manickam, M., and Sankaranarayanan, M. (2020). A medicinal chemistry perspective of drug repositioning: recent advances and challenges in drug discovery. Eur. J. Med. Chem. 195:112275. doi: 10.1016/j.ejmech.2020.112275

Quach, H., Ritchie, D., Stewart, A. K., Neeson, P., Harrison, S., Smyth, M. J., et al. (2010). Mechanism of action of immunomodulatory drugs (IMiDS) in multiple myeloma. Leukemia 24, 22-32. doi: 10.1038/leu.2009.236

Querfurth, H. W., and LaFerla, F. M. (2010). Alzheimer's disease. N. Engl. J. Med. 362, 329-344. doi: 10.1056/NEJMra0909142

Ramírez, A. E., Pacheco, C. R., Aguayo, L. G., and Opazo, C. M. (2014). Rapamycin protects against $A \beta$-induced synaptotoxicity by increasing presynaptic activity in hippocampal neurons. Biochim. Biophys. Acta 1842, 1495-1501. doi: 10.1016/ j.bbadis.2014.04.019

Raposo, C., Graubardt, N., Cohen, M., Eitan, C., London, A., Berkutzki, T., et al. (2014). CNS repair requires both effector and regulatory T cells with distinct temporal and spatial profiles. J. Neurosci. 34, 10141-10155. doi: 10. 1523/JNEUROSCI.0076-14.2014

Richardson, A., Galvan, V., Lin, A.-L., and Oddo, S. (2015). How longevity research can lead to therapies for Alzheimer's disease: the rapamycin story. Exp. Gerontol. 68, 51-58. doi: 10.1016/j.exger.2014.12.002

Riella, L. V., Paterson, A. M., Sharpe, A. H., and Chandraker, A. (2012). Role of the PD-1 pathway in the immune response. Am. J. Transplant. 12, 2575-2587. doi: 10.1111/j.1600-6143.2012.04224.x

Roboon, J., Hattori, T., Ishii, H., Takarada-Iemata, M., Le, T. M., Shiraishi, Y., et al. (2019). Deletion of CD38 suppresses glial activation and neuroinflammation in a mouse model of demyelination. Front. Cell Neurosci. 13:258. doi: 10.3389/ fncel.2019.00258

Rogers, N. K., Romero, C., SanMartín, C. D., Ponce, D. P., Salech, F., López, M. N., et al. (2020). Inverse relationship between Alzheimer's disease and cancer: how 
immune checkpoints might explain the mechanisms underlying age-related diseases. J. Alzheimers Dis. 73, 443-454. doi: 10.3233/JAD-190839

Rojanathammanee, L., Floden, A. M., Manocha, G. D., and Combs, C. K. (2015). Attenuation of microglial activation in a mouse model of Alzheimer's disease via NFAT inhibition. J. Neuroinflamm. 12:42. doi: 10.1186/s12974-015-0255-2

Rosenzweig, N., Dvir-Szternfeld, R., Tsitsou-Kampeli, A., Keren-Shaul, H., BenYehuda, H., Weill-Raynal, P., et al. (2019). PD-1/PD-L1 checkpoint blockade harnesses monocyte-derived macrophages to combat cognitive impairment in a tauopathy mouse model. Nat. Commun. 10:465. doi: 10.1038/s41467-01908352-5

Rozkalne, A., Hyman, B. T., and Spires-Jones, T. L. (2011). Calcineurin inhibition with FK506 ameliorates dendritic spine density deficits in plaque-bearing Alzheimer model mice. Neurobiol. Dis. 41, 650-654. doi: 10.1016/j.nbd.2010. 11.014

Russo, I., Caracciolo, L., Tweedie, D., Choi, S.-H., Greig, N. H., Barlati, S., et al. (2012). 3,6'-Dithiothalidomide, a new TNF- $\alpha$ synthesis inhibitor, attenuates the effect of A $\beta 1-42$ intracerebroventricular injection on hippocampal neurogenesis and memory deficit. J. Neurochem. 122, 1181-1192. doi: 10.1111/ j.1471-4159.2012.07846.x

Saibil, S. D., and Ohashi, P. S. (2020). Targeting T cell activation in immunooncology. Curr. Oncol. 27, S98-S105. doi: 10.3747/co.27.5285

Sama, D. M., Mohmmad Abdul, H., Furman, J. L., Artiushin, I. A., Szymkowski, D. E., Scheff, S. W., et al. (2012). Inhibition of soluble tumor necrosis factor ameliorates synaptic alterations and $\mathrm{Ca} 2+$ dysregulation in aged rats. PLoS One 7:e38170. doi: 10.1371/journal.pone.0038170

Santarpia, M., González-Cao, M., Viteri, S., Karachaliou, N., Altavilla, G., and Rosell, R. (2015). Programmed cell death protein-1/programmed cell death ligand-1 pathway inhibition and predictive biomarkers: understanding transforming growth factor-beta role. Transl. Lung Cancer Res. 4, 728-742. doi: 10.3978/j.issn.2218-6751.2015.12.04

Santos, R. X., Correia, S. C., Cardoso, S., Carvalho, C., Santos, M. S., and Moreira, P. I. (2011). Effects of rapamycin and TOR on aging and memory: implications for Alzheimer's disease. J. Neurochem. 117, 927-936. doi: 10.1111/j.1471-4159. 2011.07262.x

Scheinfeld, N. (2005). Adalimumab: a review of side effects. Expert. Opin. Drug Saf. 4, 637-641. doi: 10.1517/14740338.4.4.637

Schwartz, M., Arad, M., and Ben-Yehuda, H. (2019). Potential immunotherapy for Alzheimer disease and age-related dementia. Dialog. Clin. Neurosci. 21, 21-25. doi: $10.31887 /$ dnc.2019.21.1/mschwartz

Schwartz, M., and Baruch, K. (2014). Breaking peripheral immune tolerance to CNS antigens in neurodegenerative diseases: boosting autoimmunity to fightoff chronic neuroinflammation. J. Autoimmun. 54, 8-14. doi: 10.1016/j.jaut. 2014.08.002

Scott, L. J. (2013). Glatiramer acetate: a review of its use in patients with relapsingremitting multiple sclerosis and in delaying the onset of clinically definite multiple sclerosis. CNS Drugs 27, 971-988. doi: 10.1007/s40263-013-0117-3

Scuderi, C., Facchinetti, R., Steardo, L., and Valenza, M. (2020). Neuroinflammation in Alzheimer's disease: friend or foe? FASEB J. 34:1. doi: 10.1096/fasebj.2020.34.s1.00381

Shamim, D., and Laskowski, M. (2017). Inhibition of inflammation mediated through the tumor necrosis factor $\alpha$ biochemical pathway can lead to favorable outcomes in Alzheimer disease. J. Cent. Nerv. Syst. Dis. 9:1179573517722512. doi: $10.1177 / 1179573517722512$

Shi, J.-Q., Shen, W., Chen, J., Wang, B.-R., Zhong, L.-L., Zhu, Y.-W., et al. (2011). Anti-TNF- $\alpha$ reduces amyloid plaques and tau phosphorylation and induces CD11c-positive dendritic-like cell in the APP/PS1 transgenic mouse brains. Brain Res. 1368, 239-247. doi: 10.1016/j.brainres.2010.10.053

Steed, P. M., Tansey, M. G., Zalevsky, J., Zhukovsky, E. A., Desjarlais, J. R., Szymkowski, D. E., et al. (2003). Inactivation of TNF signaling by rationally designed dominant-negative TNF variants. Science 301, 1895-1898. doi: 10. $1126 /$ science. 1081297

Steeland, S., Gorlé, N., Vandendriessche, C., Balusu, S., Brkic, M., Van Cauwenberghe, C., et al. (2018). Counteracting the effects of TNF receptor-1 has therapeutic potential in Alzheimer's disease. EMBO Mol. Med. 10:e8300. doi: $10.15252 / \mathrm{emmm} .201708300$
Trapnell, C., Pachter, L., and Salzberg, S. L. (2009). TopHat: discovering splice junctions with RNA-Seq. Bioinformatics 25, 1105-1111. doi: 10.1093/ bioinformatics/btp120

Tweedie, D., Ferguson, R. A., Fishman, K., Frankola, K. A., Van Praag, H., Holloway, H. W., et al. (2012). Tumor necrosis factor- $\alpha$ synthesis inhibitor 3,6'dithiothalidomide attenuates markers of inflammation, Alzheimer pathology and behavioral deficits in animal models of neuroinflammation and Alzheimer's disease. J. Neuroinflamm. 9:106. doi: 10.1186/1742-2094-9-106

van de Donk, N. W. C. J. (2018). Immunomodulatory effects of CD38-targeting antibodies. Immunol. Lett. 199, 16-22. doi: 10.1016/j.imlet.2018.04.005

Van Skike, C. E., Jahrling, J. B., Olson, A. B., Sayre, N. L., Hussong, S. A., Ungvari, Z., et al. (2018). Inhibition of mTOR protects the blood-brain barrier in models of Alzheimer's disease and vascular cognitive impairment. Am. J. Physiol. Heart Circ. Physiol. 314, H693-H703. doi: 10.1152/ajpheart.00570. 2017

Vieira, P. L., Heystek, H. C., Wormmeester, J., Wierenga, E. A., and Kapsenberg, M. L. (2003). Glatiramer acetate (copolymer-1, copaxone) promotes Th2 cell development and increased IL-10 production through modulation of dendritic cells. J. Immunol. 170, 4483-4488. doi: 10.4049/jimmunol.170.9. 4483

Wang, X., Xia, W., Li, K., Zhang, Y., Ge, W., and Ma, C. (2019). Rapamycin regulates cholesterol biosynthesis and cytoplasmic ribosomal proteins in hippocampus and temporal lobe of APP/PS1 mouse. J. Neurol. Sci. 399, 125139. doi: 10.1016/j.jns.2019.02.022

Yiannopoulou, K. G., and Papageorgiou, S. G. (2020). Current and future treatments in Alzheimer disease: an update. J. Cent. Nerv. Syst. Dis. 12:1179573520907397. doi: 10.1177/1179573520907397

Zenaro, E., Pietronigro, E., Della Bianca, V., Piacentino, G., Marongiu, L., Budui, S., et al. (2015). Neutrophils promote Alzheimer's disease-like pathology and cognitive decline via LFA-1 integrin. Nat. Med. 21, 880-886. doi: 10.1038/nm. 3913

Zhang, B., Gaiteri, C., Bodea, L.-G., Wang, Z., McElwee, J., Podtelezhnikov, A. A., et al. (2013). Integrated systems approach identifies genetic nodes and networks in late-onset Alzheimer's disease. Cell 153, 707-720. doi: 10.1016/j.cell.2013. 03.030

Zhang, P., Kishimoto, Y., Grammatikakis, I., Gottimukkala, K., Cutler, R. G., Zhang, S., et al. (2019). Senolytic therapy alleviates A $\beta$-associated oligodendrocyte progenitor cell senescence and cognitive deficits in an Alzheimer's disease model. Nat. Neurosci. 22, 719-728. doi: 10.1038/s41 593-019-0372-9

Zhao, J., and Ji, R.-R. (2019). Anti-PD-1 treatment as a neurotherapy to enhance neuronal excitability, synaptic plasticity and memory. bioRxiv [Preprint], doi: $10.1101 / 870600$

Zhou, M., Xu, R., Kaelber, D. C., and Gurney, M. E. (2020). Tumor Necrosis Factor (TNF) blocking agents are associated with lower risk for Alzheimer's disease in patients with rheumatoid arthritis and psoriasis. PLoS One 15:e0229819. doi: 10.1371/journal.pone.0229819

Ziv, Y., Ron, N., Butovsky, O., Landa, G., Sudai, E., Greenberg, N., et al. (2006). Immune cells contribute to the maintenance of neurogenesis and spatial learning abilities in adulthood. Nat. Neurosci. 9, 268-275. doi: 10.1038/nn1629

Conflict of Interest: The authors declare that the research was conducted in the absence of any commercial or financial relationships that could be construed as a potential conflict of interest.

The handling editor declared a past co-authorship with several of the authors GD, $\mathrm{CB}, \mathrm{RB}$, and GC.

Copyright (c) 2020 Munafò, Burgaletto, Di Benedetto, Di Mauro, Di Mauro, Bernardini and Cantarella. This is an open-access article distributed under the terms of the Creative Commons Attribution License (CC BY). The use, distribution or reproduction in other forums is permitted, provided the original author(s) and the copyright owner(s) are credited and that the original publication in this journal is cited, in accordance with accepted academic practice. No use, distribution or reproduction is permitted which does not comply with these terms. 